\title{
Effects of Viscosity and Type of Oil on Dynamic Behaviors of Friction of Hydraulic Cylinder*
}

\author{
Xuan Bo TRAN**, Akinori MATSUI***, Hideki YANADA**
}

This paper deals with the dynamic behaviors of friction observed in a hydraulic cylinder. Yanada and his coworkers have modified the LuGre model, which is the most widely utilized friction model, by incorporating lubricant film dynamics into the LuGre model and have shown that the dynamic friction behaviors of a hydraulic actuator can be simulated by the modified LuGre model with a relatively good accuracy. In addition, a method to identify the dynamic parameters included in the model has been proposed. However, the experiments were conducted using one type of oil at a fixed temperature. It has not been made clear how the dynamic behaviors of friction are affected by viscosity and type of oil. In this paper, the effects of the viscosity and type of oil on the dynamic behaviors of friction are examined using a hydraulic cylinder. It is shown that the type of oil affects the size of the hysteresis loop of the friction force-velocity curve to some degree and that the viscosity hardly has influence on the dynamic friction behaviors. It is also shown that the time constant of lubricant film dynamics is increased with increasing viscosity but its variation is relatively small and that the bristle stiffness and microviscous coefficient are not affected by the viscosity and the type of oil. A simple modification of the modified LuGre model taking the effects of the oil temperature into consideration is made. Comparisons between experimental and simulation results show that the improved model is appropriate.

Key words : Friction, Hydraulic actuator, Mathematical model, Viscosity, Type of oil, Dynamic parameter

\section{Introduction}

Accurate modeling of static and dynamic characteristics of a fluid power actuator is very important to analyze the performance of or to predict the behaviors of a fluid power system. Mathematical models to describe the steady-state friction characteristics have been proposed ${ }^{1)-3)}$ and are widely used to analyze the steady-state characteristics of a fluid power actuator. However, those models are useless to predict dynamic behaviors of the actuator especially when the actuator repeats start and stop.

Several mathematical models that describe the dynamic behaviors of friction have been proposed ${ }^{4)-6)}$ and among them, the LuGre model ${ }^{4)}$ is most widely utilized. However, all those models cannot simulate well the friction behaviors of hydraulic actuators in the sliding regime ${ }^{7), 8)}$. A modification to the LuGre model has been done by incorporating lubricant film dynamics into the model and it has been shown that the proposed model, called the modified LuGre model, can

\footnotetext{
* Manuscript received June 29, 2009

** Toyohashi University of Technology

(1-1, Hibarigaoka, Tempaku-cho, Toyohashi, Japan)

E-mail : yanada@mech.tutac.jp

*** Sintokogio Ltd.

(3-1, Honohara, Toyokawa, Japan)
}

simulate dynamic behaviors of friction observed with a hydraulic cylinder with a relatively good accuracy ${ }^{8}$. In addition, a method to identify the dynamic parameters, $\sigma_{0}$ and $\tau_{h}$, included in the modified LuGre model has been proposed $^{9)}$.

Even though the viscosity grade is the same among oils, the friction characteristics of hydraulic actuators are affected by the type of oil due to different additives mixed in each type of $\mathrm{oil}^{10)}$. In addition, the friction characteristics are affected by the viscosity of oil, especially at high velocities and may be affected also at low velocities ${ }^{11)}$. Therefore, it is very probable for the dynamic behaviors of friction (or the unsteady-state friction characteristics) to be affected by those factors. However, the experiment that examined the dynamic behaviors of friction of a hydraulic actuator was conducted at a fixed temperature using only one type of $\mathrm{oil}^{7 \mathrm{7}-9)}$.

In this paper, friction experiments are made to examine the effects of viscosity and type of oil on dynamic behaviors of friction of hydraulic cylinder under different viscosities using some types of oil. Effects of the viscosity on all static and dynamic parameters of the modified LuGre model are investigated and a simple modification to the modified LuGre model taking the effects of oil temperature (viscosity) into consideration is proposed. Comparisons of the simulation results with measured ones at different oil temperatures are made. 


\section{Nomenclature}

a : acceleration

$A_{i} \quad$ : piston area $(i=1,2)$

$C_{i} \quad$ : temperature correction coefficient $(i=1,2)$

$F_{c}:$ Coulomb friction force

$F_{r}$ : friction force

$F_{r s s}:$ steady-state friction force

$F_{s}:$ maximum static friction force

$g \quad$ : Stribeck function

$h$ : dimensionless unsteady-state lubricant film thickness

$h_{\mathrm{ss}}:$ dimensionless steady-state lubricant film thickness

$K_{f} \quad$ : proportional constant for lubricant film thickness

$m$ : load mass

$n \quad$ : exponent for Stribeck curve

$p_{i} \quad$ : pressure $(i=1,2)$

$p_{s} \quad:$ supply pressure

$t \quad:$ time

u : control input (servo current)

$v \quad$ : velocity

$v_{b}:$ upper $($ for $v>0)$ or lower $($ for $v<0)$ limit of velocity in negative resistance regime

$v_{s} \quad:$ Stribeck velocity

$z \quad$ : mean deflection of bristles

$\theta \quad$ : oil temperature

$\theta_{0}:$ standard oil temperature

$\sigma_{0}:$ stiffness of bristles

$\sigma_{1}:$ micro-viscous friction coefficient for bristles

$\sigma_{2}:$ viscous friction coefficient

$\tau_{h}$ : time constant for lubricant film dynamics

$\tau_{h p}:$ time constant for acceleration period

$\tau_{h n}:$ time constant for deceleration period

$\tau_{h 0}:$ time constant for dwell period

\section{Experimental Apparatus}

Figure 1 shows a schema of the experimental apparatus used. The experimental apparatus is the same as that used in the previous papers ${ }^{8), 9)}$ and its details are omitted. The friction force is obtained from the equation of motion of the hydraulic piston using the measured values of the pressures in the cylinder chambers and the acceleration of the piston as follows:

$$
F_{r}=p_{1} A_{1}-p_{2} A_{2}-m a
$$

The supply pressure, $p_{s}$, was kept at $5 \mathrm{MPa}$. In order to examine the effects of viscosity and type of oil on dynamic friction behaviors, five types of oil shown in Table 1 were used. Relation between viscosity and temperature for the five oils is shown in Fig. 2. The effect of type of oil was examined

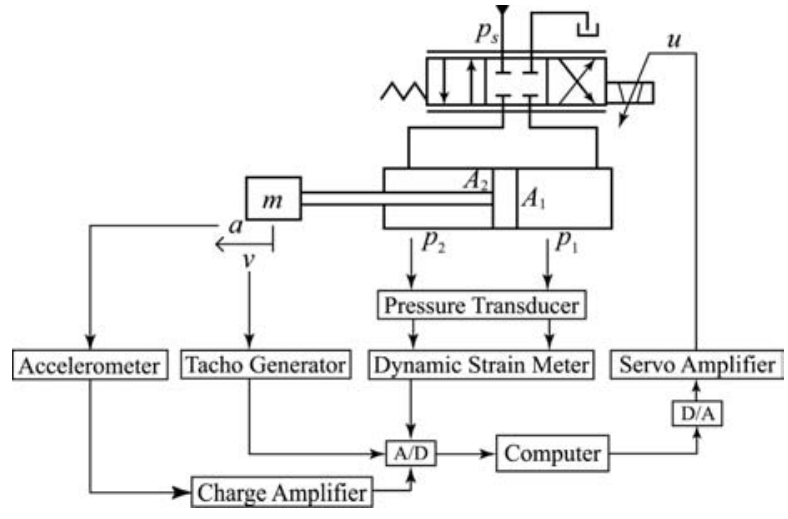

Fig. 1 Schema of experimental apparatus

Table 1 Test oils

\begin{tabular}{|c|l|l|c|}
\hline Oil No. & $\begin{array}{l}\text { Name and viscosity } \\
\text { grade }\end{array}$ & \multicolumn{1}{|c|}{ Maker } & $\begin{array}{c}\text { Viscosity } \\
\left(\text { at } 34^{\circ} \mathrm{C}\right)\end{array}$ \\
\hline Oil 1 & $\begin{array}{l}\text { Daphne Super } \\
\text { Hydraulic Fluid, 46 }\end{array}$ & $\begin{array}{l}\text { Idemitsu Kosan } \\
\text { Co.Ltd }\end{array}$ & $55.0 \mathrm{mPa} \cdot \mathrm{s}$ \\
\hline Oil 2 & Super Hyrando, 46 & $\begin{array}{l}\text { Idemitsu Kosan } \\
\text { Co.Ltd }\end{array}$ & $57.6 \mathrm{mPa} \cdot \mathrm{s}$ \\
\hline Oil 3 & $\begin{array}{l}\text { Daphne Super } \\
\text { Hydro, 22 }\end{array}$ & Nippon Oil Corp. & $25.0 \mathrm{mPa} \cdot \mathrm{s}$ \\
\hline Oil 4 & General Panol, 22 & $\begin{array}{l}\text { General Sekiyu } \\
\text { K.K. }\end{array}$ & $26.3 \mathrm{mPa} \cdot \mathrm{s}$ \\
\hline Oil 5 & $\begin{array}{l}\text { Daphne Super Multi } \\
\text { Oil, 2 }\end{array}$ & $\begin{array}{l}\text { Idemitsu Kosan } \\
\text { Co.Ltd }\end{array}$ & $3.0 \mathrm{mPa} \cdot \mathrm{s}$ \\
\hline
\end{tabular}

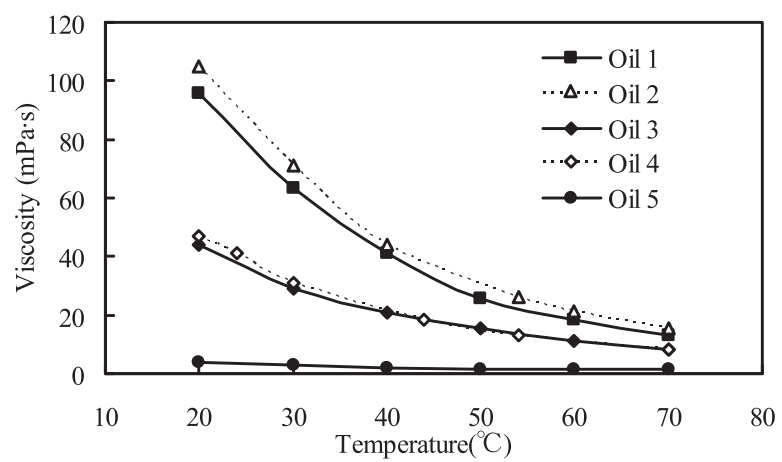

Fig. 2 Relation between viscosity and temperature of test oils

by using four types of oil, Oils 1 to 4 at the same viscosity of $35 \mathrm{mPa} \cdot \mathrm{s}$, which was realized by adjusting temperature, while the effect of viscosity was examined by changing temperature of Oil 1 and by using three types of oil which have different viscosity grades, Oils 1,3 , and 5 , at $34^{\circ} \mathrm{C}$. The temperature at the outlet of the return line was about $1{ }^{\circ} \mathrm{C}$ lower than that in the oil tank. This means that the mean temperature in the hydraulic cylinder is almost equal to that in the oil tank.

\section{Modified LuGre Model}

The modified LuGre model ${ }^{8)}$ is described below in short. 
i ) Equations corresponding to the LuGre model

$$
\begin{aligned}
& \frac{d z}{d t}=v-\frac{\sigma_{0} z}{\mathrm{~g}(v, h)} v \\
& g(v, h)=F_{c}+\left[(1-h) F_{s}-F_{c}\right] e^{-\left(v / v_{s}\right)^{n}} \\
& F_{r}=\sigma_{0} z+\sigma_{1} \frac{d z}{d t}+\sigma_{2} v
\end{aligned}
$$

ii ) Lubricant film dynamics

$$
\begin{aligned}
& \frac{d h}{d t}=\frac{1}{\tau_{h}}\left(h_{s s}-h\right) \\
& \tau_{h}=\left\{\begin{array}{l}
\tau_{h p}\left(v \neq 0, h \leq h_{s s}\right) \\
\tau_{h n}\left(v \neq 0, h>h_{s s}\right) \\
\tau_{h 0}(v=0)
\end{array}\right. \\
& h_{s s}=\left\{\begin{array}{l}
K_{f}|v|^{2 / 3}\left(|v| \leq\left|v_{b}\right|\right) \\
K_{f}\left|v_{b}\right|^{2 / 3}\left(|v|>\left|v_{b}\right|\right)
\end{array}\right. \\
& K_{f}=\left(1-F_{c} / F_{s}\right)\left|v_{b}\right|^{-2 / 3}
\end{aligned}
$$

iii) Steady-state friction characteristic

$$
F_{r s s}=F_{c}+\left[\left(1-h_{s s}\right) F_{s}-F_{c}\right] \mathrm{e}^{-\left(v / v_{s}\right)^{n}}+\sigma_{2} v
$$

Steady-state friction characteristics are affected by oil viscosity caused by the variation of oil temperature. As shown later in Section 5, the oil temperature affects the magnitudes of $F_{s}$ and $F_{c}$, but hardly affects the other static parameters. Taking these and the friction model proposed in ref. 12) into consideration, the Stribeck function and the steady-state characteristic are modified as follows:

$$
\begin{aligned}
g(v, h) & =F_{c}+C_{1}\left(\frac{\theta}{\theta_{0}}-1\right) \\
& +\left[(1-h) F_{s}-F_{c}+C_{2}\left(\frac{\theta}{\theta_{0}}-1\right)\right] e^{-\left(v / v_{s}\right)^{n}} \\
F_{r s s}= & F_{c}+C_{1}\left(\frac{\theta}{\theta_{0}}-1\right) \\
+ & {\left[\left(1-h_{s s}\right) F_{s}-F_{c}+C_{2}\left(\frac{\theta}{\theta_{0}}-1\right)\right] e^{-\left(v / v_{s}\right)^{n}}+\sigma_{2} v }
\end{aligned}
$$

where $\theta$ is the temperature of a lubricant, for a hydraulic actuator, the mean oil temperature in it and $\theta_{0}$ is the standard temperature at which the static parameters are identified.

\section{Results and Discussions}

Every experiment was conducted three times. The repeatability was good and the difference among three measurements at an experimental condition was less than $7 \%$.

\subsection{Steady-State Friction Characteristics}

Figure 3 shows steady-state friction characteristics measured for Oils 1 to 4 at the same viscosity of $35 \mathrm{mPa} \cdot \mathrm{s}$.

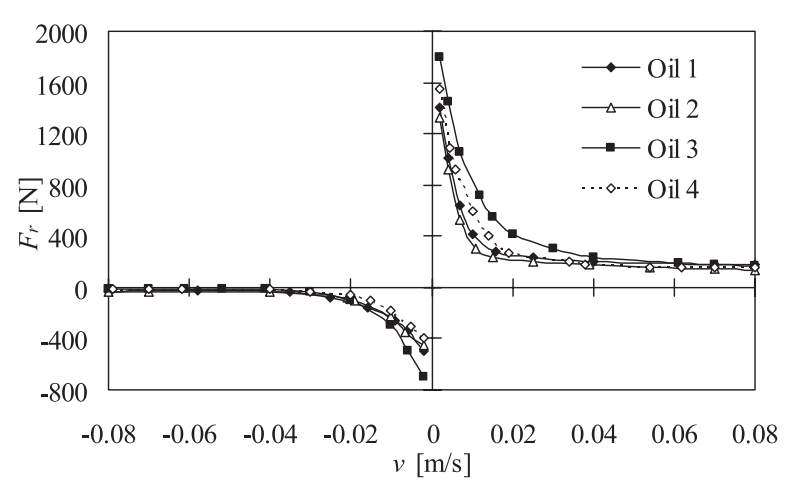

Fig. 3 Steady-state friction characteristics for Oils 1 to 4 at $35 \mathrm{mPa} \cdot \mathrm{s}$

As can be seen from Fig. 3, there are differences in the steady-state friction characteristics among the four oils, especially at low velocities. Oils 1 and 2 seem to have the same friction characteristics in both positive velocity range (extending stroke) and negative one (retracting stroke) . However, the friction characteristics for Oils 3 and 4 are different from each other and from those for Oils 1 and 2 . The magnitude of the friction force for Oil 3 is much larger than those for Oils 1 and 2 in both velocity ranges. At high velocities, the friction characteristics seem to be the same among the four oils.

Figure 4 shows steady-state friction characteristics for Oil 1 measured at the oil viscosities of 83,35 , and $25 \mathrm{mPa} \cdot \mathrm{s}$. These viscosities were obtained by changing the oil temperature. As can be seen from Fig. 4, the magnitude of the friction force is increased with decreasing viscosity and the degree of the increase is larger in the negative velocity range than in the positive one. The reason that the temperature dependence of friction depends on the moving direction of the piston is not clear at present.

Figure 5 shows steady-state friction characteristics for three types of oil having different viscosity grades, Oils 1, 3, and 5 , measured at $34^{\circ} \mathrm{C}$. Viscosities of the three oils at $34^{\circ} \mathrm{C}$ are 55,25 , and $3 \mathrm{mPa} \cdot \mathrm{s}$ for Oils 1,3 , and 5 , respectively. The

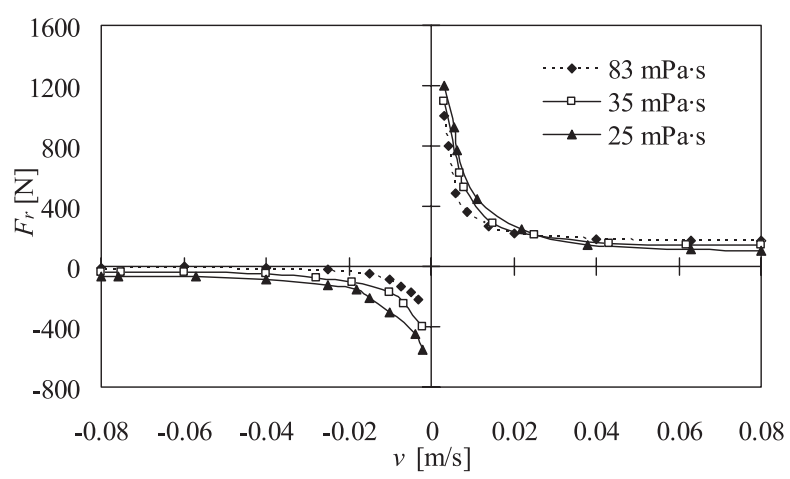

Fig. 4 Steady-state friction characteristics for Oil 1 at viscosities of 83,35 , and $25 \mathrm{mPa} \cdot \mathrm{s}$ 


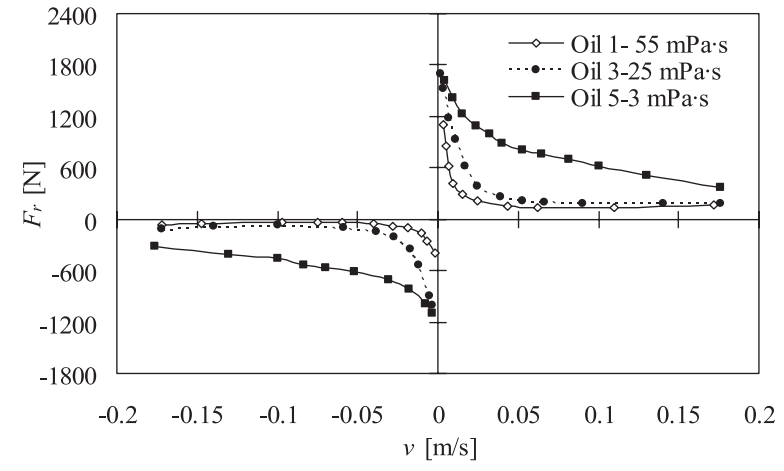

Fig. 5 Steady-state friction characteristics for Oils 1, 3, and 5 at $34^{\circ} \mathrm{C}$

steady-state friction force is increased with decreasing viscosity grade.

The difference in the magnitude of the friction force results not only from the effect of the value of the viscosity but also from the difference in the type of oil. Taking the results shown in Fig. 4 into account, the effect of the type of oil may be larger than that of the viscosity.

Table 2 shows the values of the static parameters of the modified LuGre model for Oil 1 at three cases of viscosity; the static parameters were identified from the measured steadystate friction characteristics in Fig. 4. As shown in Table 2, the values of $v_{s}, n, \sigma_{2}$, and $v_{b}$ are hardly changed with viscosity while the values of $F_{s}$ and $F_{c}$ are varied. The value of $F_{s}$ is increased with decreasing viscosity; the increase of $F_{s}$ is very small in the positive velocity range and large in the negative one. The magnitude of $F_{c}$ is decreased in the positive velocity range but increased in the negative one. A similar result was also obtained for Oil 3 when the oil

Table 2 Values of static parameters at different viscosities for Oil 1

\begin{tabular}{|c|c|c|c|c|c|c|c|}
\hline \multicolumn{2}{|c|}{ Parameters } & $\begin{array}{c}F_{s} \\
{[\mathrm{~N}]}\end{array}$ & $\begin{array}{c}F_{c} \\
{[\mathrm{~N}]}\end{array}$ & $\begin{array}{c}v_{s} \\
{[\mathrm{~m} / \mathrm{s}]}\end{array}$ & $n$ & $\begin{array}{c}\sigma_{2} \\
{[\mathrm{Ns} / \mathrm{m}]}\end{array}$ & $\begin{array}{c}v_{b} \\
{[\mathrm{~m} / \mathrm{s}]}\end{array}$ \\
\hline $\begin{array}{c}83 \\
\mathrm{mPa} \cdot \mathrm{s} \\
\left(24^{\circ} \mathrm{C}\right)\end{array}$ & $v>0$ & 1500 & 180 & $\begin{array}{c}9.8 \\
\times 10^{-3}\end{array}$ & 0.95 & 105 & $\begin{array}{c}3.5 \\
\times 10^{-2}\end{array}$ \\
\cline { 2 - 8 } & $v<0$ & -420 & 0 & $\begin{array}{c}-1.0 \\
\times 10^{-2}\end{array}$ & 0.71 & 150 & $\begin{array}{c}-3.5 \\
\times 10^{-2}\end{array}$ \\
\hline $\begin{array}{c}35 \\
\mathrm{mPa} \cdot \mathrm{s} \\
\left(44^{\circ} \mathrm{C}\right)\end{array}$ & $v>0$ & 1623 & 165 & $\begin{array}{c}1.0 \\
\times 10^{-2}\end{array}$ & 0.92 & 100 & $\begin{array}{c}3.5 \\
\times 10^{-2}\end{array}$ \\
\cline { 2 - 8 } & $v<0$ & -698 & -22 & $\begin{array}{c}-1.0 \\
\times 10^{-2}\end{array}$ & 0.70 & 152 & $\begin{array}{c}-3.5 \\
\times 10^{-2}\end{array}$ \\
\hline $\begin{array}{c}25 \\
\mathrm{mPa} \cdot \mathrm{s} \\
\left(54{ }^{\circ} \mathrm{C}\right)\end{array}$ & $v>0$ & 1694 & 140 & $\begin{array}{c}1.0 \\
\times 10^{-2}\end{array}$ & 0.91 & 110 & $\begin{array}{c}3.5 \\
\times 10^{-2}\end{array}$ \\
\cline { 2 - 8 } & $v<0$ & -878 & -48 & $\begin{array}{c}-1.2 \\
\times 10^{-2}\end{array}$ & 0.72 & 145 & $\begin{array}{c}-3.5 \\
\times 10^{-2}\end{array}$ \\
\hline
\end{tabular}

Table 3 Values of $C_{1}, C_{2}$, and $\theta_{0}$ for Oil 1

\begin{tabular}{|c|c|c|c|}
\hline Parameter & $C_{1}[\mathrm{~N}]$ & $C_{2}[\mathrm{~N}]$ & $\theta_{0}\left({ }^{\circ} \mathrm{C}\right)$ \\
\cline { 1 - 3 }$v>0$ & -40 & 50 & \multirow{2}{*}{44} \\
\cline { 1 - 3 }$v<0$ & 50 & 150 & \\
\hline
\end{tabular}

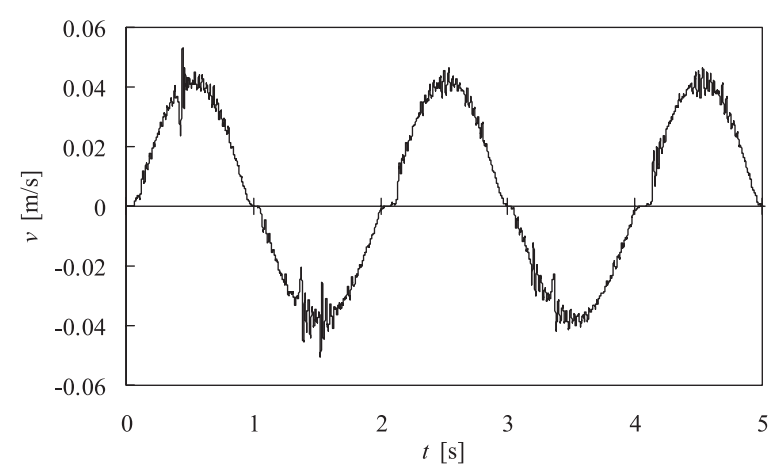

(a) Velocity variation

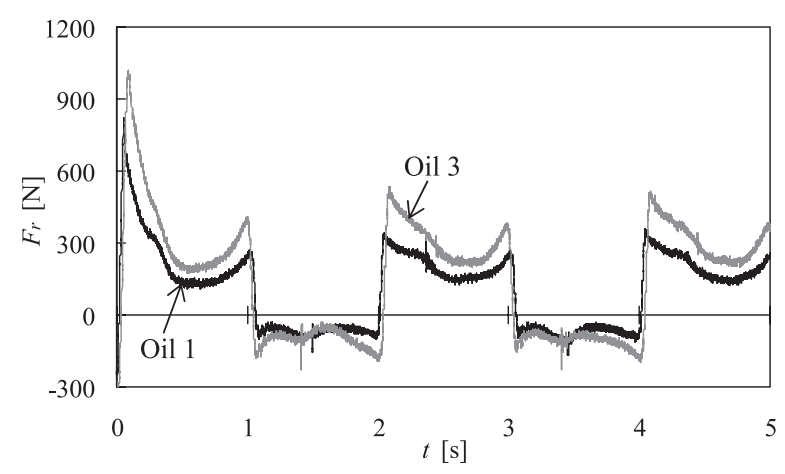

(b) Friction force variation

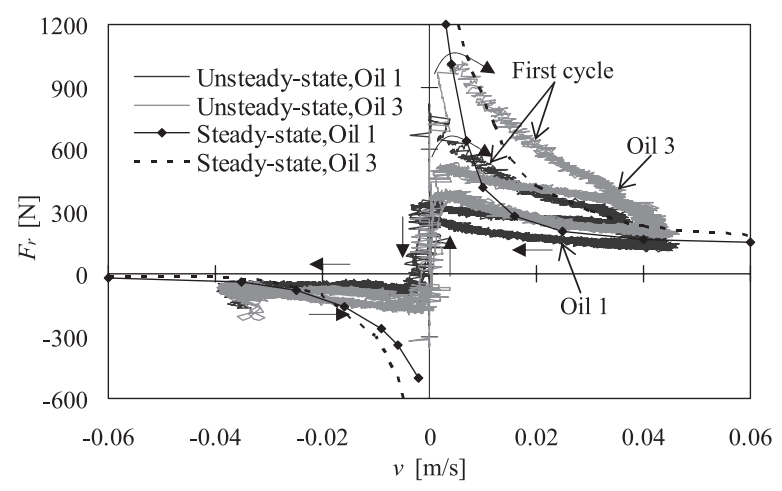

(c) Friction force vs. velocity

Fig. 6 Unsteady-state friction characteristics for Oils 1 and 3 at $35 \mathrm{mPa} \cdot \mathrm{s}$ under small velocity variation

temperature was changed except that the magnitude of $F_{c}$ was increased with decreasing viscosity in both velocity ranges. Table 3 shows the values of $C_{1}$ and $C_{2}$ identified when $44^{\circ} \mathrm{C}(35 \mathrm{mPa} \cdot \mathrm{s})$ was chosen as the standard oil temperature $\theta_{0}$. The steady-state friction characteristics can well be simulated by using the identified parameters.

\subsection{Unsteady-State Friction Characteristics}

Figure 6 shows unsteady-state friction characteristics measured for Oils 1 and 3 at $35 \mathrm{mPa} \cdot \mathrm{s}$. Fig. 6(a) shows a sinusoidal velocity variation of the hydraulic piston and Fig. 6 (b) shows the friction forces measured for the two oils. The velocity variation range was chosen to be smaller than 0.045 
$\mathrm{m} / \mathrm{s}$ in order for the effect of the type of oil to become clear. As shown in Fig. 6(b), the same friction force variation is repeated after the first cycle. Similarly to the steady-state friction characteristics shown in Fig. 3, the friction force for Oil 3 is larger, especially in the positive velocity range, than that for Oil 1. This result can be seen also in Fig. 6(c), which shows friction force-velocity curves for Oils 1 and 3 and compares the steady-state and unsteady-state friction characteristics as well. In addition, it is observed from Fig. 6 (c) that the size of the hysteresis loop of the friction forcevelocity curve for Oil 3 is larger than that for Oil 1. This result suggests that the type of oil has an influence also on the unsteady-state friction characteristic. The unsteady-state friction characteristics measured for Oils 2 and 4 are similar to that for Oil 1 and are not shown in Figs. 6(b) and 6(c) in order to avoid confusion.

Figure 7 shows experimental results obtained in a larger velocity range than in Fig. 6 . The difference in the size of the hysteresis loop between Oils 1 and 3 becomes small when the velocity is increased. The results shown in Figs. 6 and 7 suggest that when the lubricant film is formed by entering the fluid lubrication regime and the acceleration and deceleration are relatively large, the effect of the type of oil becomes small.

Figure 8 shows unsteady-state friction characteristics measured for Oil 1 at viscosities of 83 and $25 \mathrm{mPa} \cdot \mathrm{s}$. The velocity variation for Fig. 8 is the same as that in Fig. 6 (a). It is shown from Fig. 8 that the friction force is hardly changed with the viscosity in the positive velocity range except that the friction force is larger for lower viscosity than for higher one in the first acceleration period. In the negative velocity range, the magnitude of the friction force is increased with decreasing viscosity. These results correspond to the steadystate friction characteristics. Figure 8 also shows that the size of the hysteresis loop is almost the same for two cases of the viscosity. This means that the viscosity hardly affects the size of the hysteresis loop. This result is different from the one obtained by Hess and Soom ${ }^{11}$. They obtained the result that the size of the hysteresis loop becomes smaller with decreasing viscosity. However, they used oils with different viscosity grades to change the viscosity. It is believed that the effect of type of oil appeared in their result.

Figure 9 shows unsteady-state friction characteristics for three types of oil having different viscosity grades, Oils 1, 3, and 5 , measured at $34^{\circ} \mathrm{C}$ and obtained when the velocity was varied as shown in Fig. 6(a). In Fig. 9, the friction forcevelocity curve during the first cycle of the velocity variation is not shown to avoid confusion. For Oils 1 and 3 , the

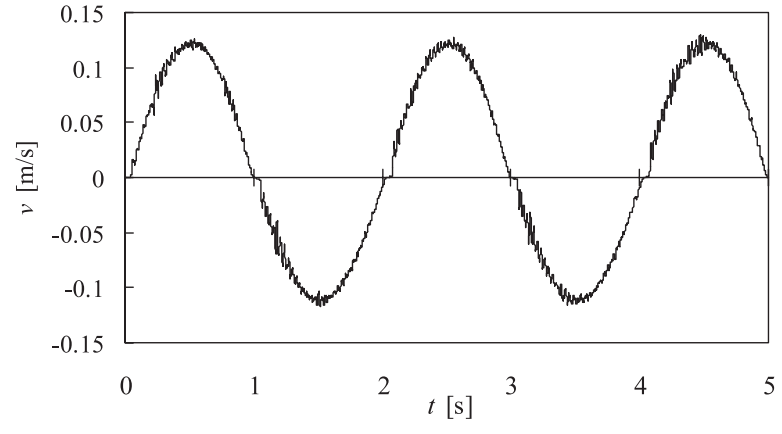

(a) Velocity variation

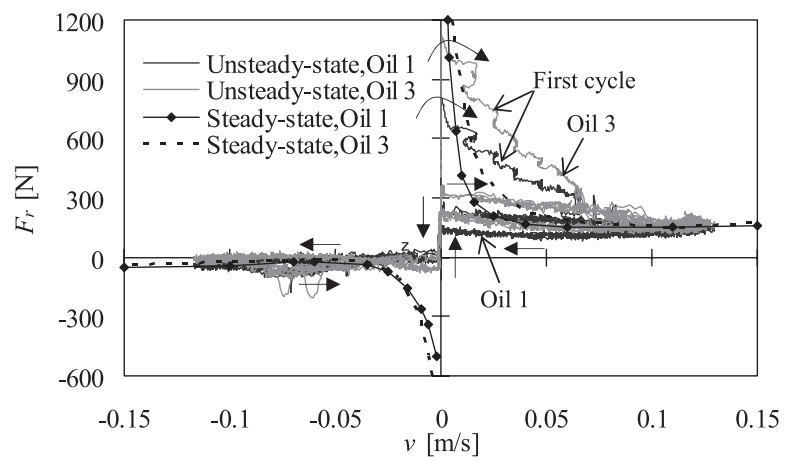

(b) Friction force vs. velocity

Fig. 7 Unsteady-state friction characteristics for Oils 1 and 3 at $35 \mathrm{mPa} \cdot \mathrm{s}$ under large velocity variation

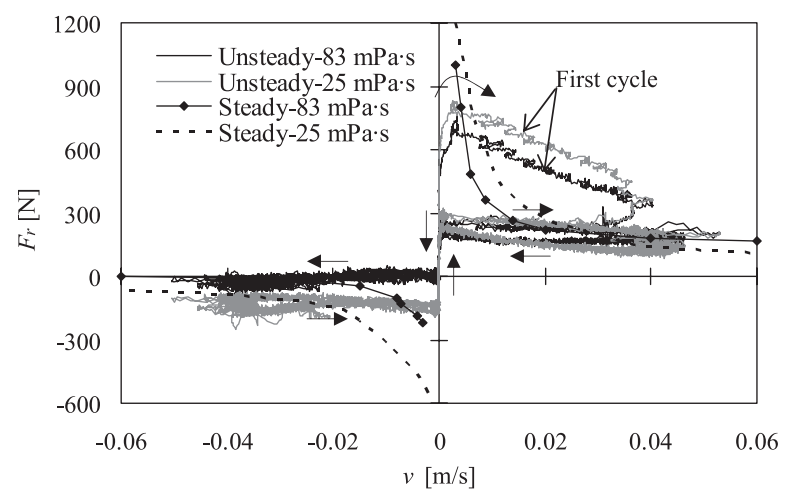

Fig. 8 Unsteady-state friction characteristics for Oil 1 at viscosities of 83 and $25 \mathrm{mPa} \cdot \mathrm{s}$

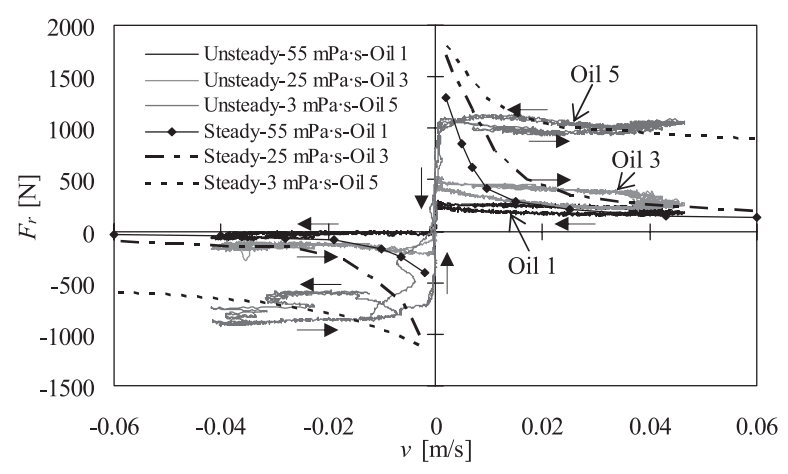

Fig. 9 Unsteady-state friction characteristics for Oils 1, 3, and 5 at $34^{\circ} \mathrm{C}$ (after first cycle) 
unsteady-state friction tends to rotate clockwise in the positive velocity range and counterclockwise in the negative one. Such a phenomenon of counter-clockwise rotation was apt to be observed in the negative velocity range when the amplitude and the frequency of the velocity variation were small. It was considered that a certain rate-dependent deformation characteristic of the rubber packing, which results from a viscoelastic nature of the rubber, may cause such behavior ${ }^{8)}$.

However, for Oil 5, the unsteady-state friction tends to rotate counterclockwise in both positive and negative ranges of the velocity. The friction force during acceleration is smaller than that during the deceleration except for the first half cycle (not shown in Fig. 9) . This means that such peculiar dynamic behaviors of friction tend to be observed when acceleration/deceleration is small and/or oil viscosity is very low. The size of the hysteresis loop is also different among Oils 1, 3, and 5. Taking into account the results shown in Figs. 6(c) and 8 as well as simulation results described later, it is considered that the difference in the size of the hysteresis loop is not affected by viscosity in itself but mainly by type of oil.

Figure 10 shows the relation between the time constant for lubricant film dynamics and viscosity for Oils 1,3 , and 5 obtained at different temperatures using the method proposed in the previous paper ${ }^{9)}$. As can be seen from Fig. 10 , the time constant is increased with increasing viscosity irrespective of the difference in the type of oil.

Figure 11 is a simulation result and shows the effect of the length of the time constant on the dynamic behavior of friction. The velocity wave form shown in Fig. 6(a) was used. One set of the time constants was chosen as that of the minimum values shown in Fig. 10 and large values which significantly exceed the maximum values shown in Fig. 10 were selected as another set of time constants. Other parameters used in the simulation were taken from Table 2

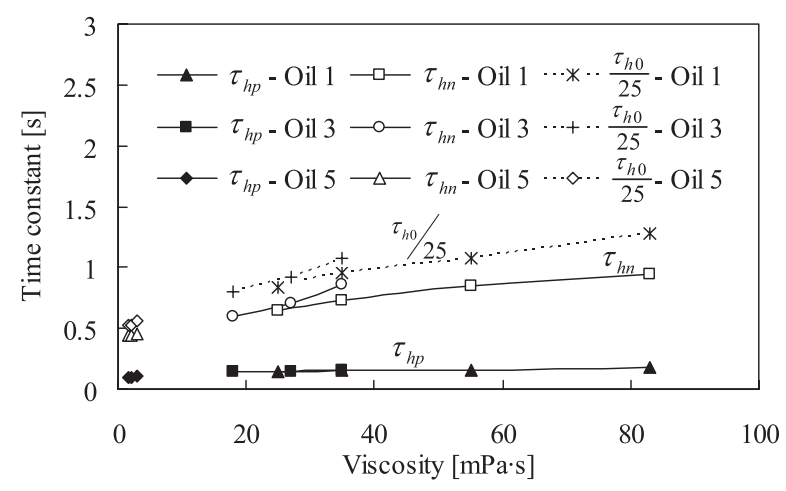

Fig. 10 Relation between time constants and viscosity

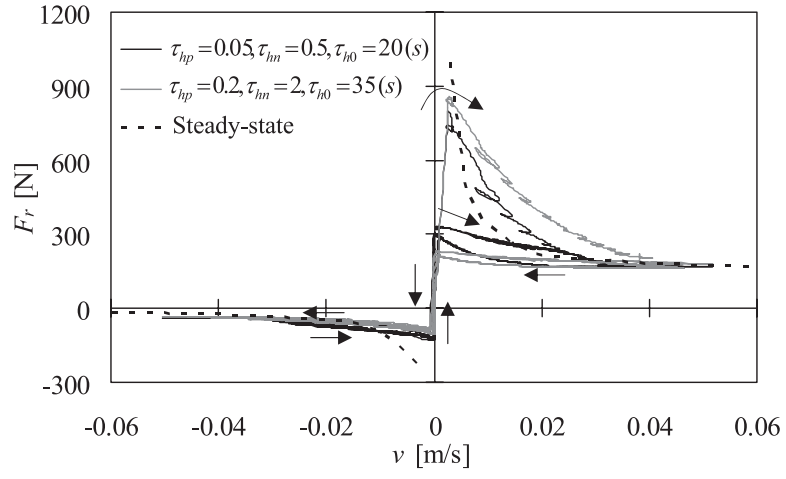

Fig. 11 Effect of time constant on friction behavior (simulation)

(at $44^{\circ} \mathrm{C}$ ). The values of the bristle stiffness, $\sigma_{0}$, and microviscous coefficient, $\sigma_{1}$, used are $1 \times 10^{8} \mathrm{~N} / \mathrm{m}$ and $0.1 \mathrm{Ns} / \mathrm{m}$, respectively. Figure 11 shows that an increase in the time constant brings about an increase in the break-away force (the maximum friction force observed immediately after start), a decrease in the friction force after the first acceleration period, and a decrease in the size of the hysteresis loop. However, simulations showed that the variation of the time constant in such a range as shown in Fig.10 hardly affects the magnitude of the break-away force, the magnitude of friction force after the first acceleration period, and the size of the hysteresis loop. Therefore, there is no need to incorporate the variation of the time constants with viscosity into the modified LuGre model.

Using the values of the static parameters in Table 2 and of the time constants in Fig. 10, values of the stiffness of the bristle, $\sigma_{0}$, and of the micro-viscous friction coefficient for bristles, $\sigma_{1}$, were identified at each viscosity using the method proposed in the previous paper ${ }^{9)}$. The identification results showed that the values of $\sigma_{0}=1 \times 10^{8} \mathrm{~N} / \mathrm{m}$ and $\sigma_{1}=0.1$ $\mathrm{Ns} / \mathrm{m}$ are appropriate for all the cases of viscosity, which are the same as the values obtained in the previous paper". These results suggest that the values of $\sigma_{0}$ and $\sigma_{1}$ do not depend on the viscosity and type of oil.

The dynamic parameters in the modified LuGre model are not practically affected by the viscosity and type of oil but the size of the hysteresis loop is affected to some degree by those factors as shown in Figs. 6(c) and 9. Simulations showed that the size of the hysteresis loop is affected by a few static parameters, $F_{s}, F_{c}$ and $v_{s}$, but that no definite relations can be seen between the viscosity and those parameters.

Figure 12 shows comparisons between experimental and simulation results of the unsteady-state friction characteristics for Oil 1 at two temperatures of $24^{\circ} \mathrm{C}$ and $54^{\circ} \mathrm{C}$. Figure 13 


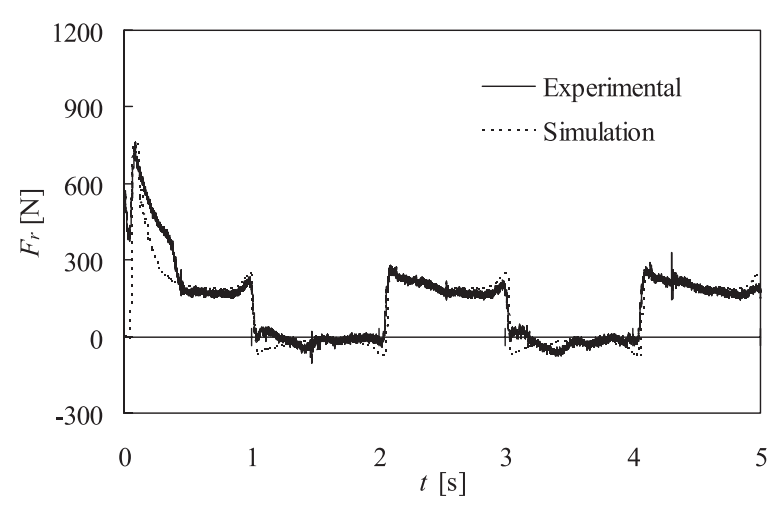

(a) $24{ }^{\circ} \mathrm{C}(83 \mathrm{mPa} \cdot \mathrm{s})$

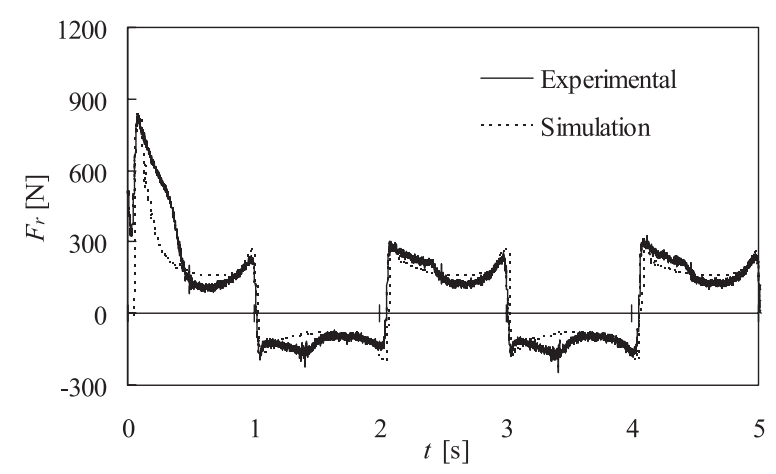

(b) $54{ }^{\circ} \mathrm{C}(25 \mathrm{mPa} \cdot \mathrm{s})$

Fig. 12 Comparison between experimental and simulation results for Oil 1 at two temperatures

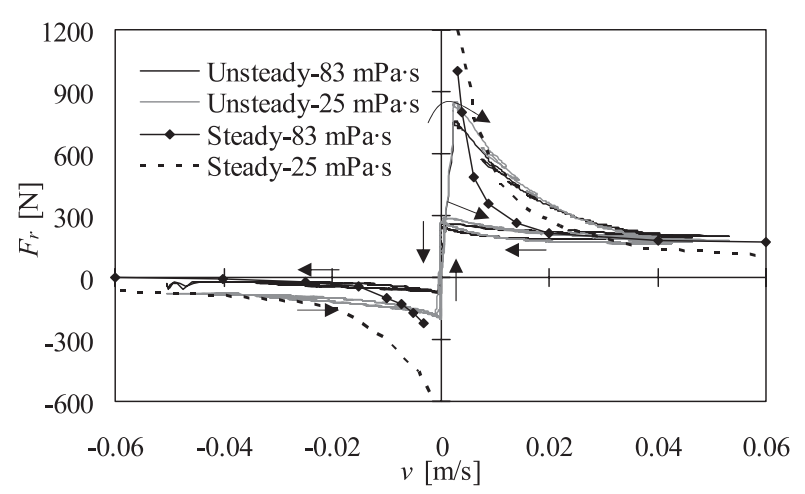

Fig. 13 Simulation results of unsteady-state friction characteristics at two temperatures for Oil 1 corresponding to Fig. 8

shows the friction force-velocity curves obtained from the simulation results shown in Fig. 12 and the velocity wave form in Fig. 6(a) and needs to be compared with the friction characteristics shown in Fig. 8. Figure 12 shows that the simulation results agree relatively well with the experimental ones at each oil temperature except for the first acceleration period. In Fig. 13, the size of the hysteresis loop is almost the same for two cases of the oil temperature. This result agrees with the experimental result shown in Fig. 8.

\section{Conclusion}

In this paper, dynamic behaviors of friction of a hydraulic cylinder are experimentally examined at various temperatures using different types of oil. The effects of the viscosity and type of oil on the dynamic parameters are examined as well. It is shown that the size of the hysteresis loop of the friction force-velocity curve is affected to some degree by the type of oil and is hardly affected by the viscosity. The time constant for lubricant film dynamics is increased with increasing viscosity irrespective of the difference in the type of oil. However, the variation of the time constant with viscosity is not large and needs not be incorporated into the friction model. The bristle stiffness and micro-viscous coefficient are not affected by the oil viscosity and type of oil. Dynamic friction behaviors can be simulated relatively well by modifying the Stribeck function of the modified LuGre model taking the effect of temperature into account.

\section{Acknowledgements}

The author would like to express their gratitude to Nobuhiko Yoshigaki for his help in part of the experiments.

\section{References}

1 ) Armstrong-Helouvry,B:-Control of Machines with Friction, Kluwer Academic Publishers, (1991)

2 ) Armstrong-Helouvry, B., Dupont, P., Canudas de Wit, C: A Survey of Models, Analysis Tools and Compensation Methods for the Control of Machines with Friction, Automatica, 30-7, 1083/1138 (1994)

3 ) Hibi, A., Ichikawa, T.: Mathematical Model of the Torque Characteristics for Hydraulic Motors, Bull. JSME, 20-143, 616/621 (1977)

4 ) Canudas de Wit, C., Olsson, H., Åström, K. J., Linschinsky, P. A New Model for Control of Systems with Friction, IEEE Trans. Automatic Control, 40-3, 419/425 (1995)

5 ) Swevers, J., Al-Bencer, F., Ganseman, C. G., Prajogo, T.: An Integrated Friction Model Structure with Improved Presliding Behavior for Accurate Friction Compensation, IEEE Trans. Automatic Control, 45-4, 675/686 (2000)

6 ) Dupont, P., Hayward, V., Armstrong, B., Altpeter, F.: Single StateElastoplastic Friction Models, IEEE Trans. Automatic Control, 47-5, 787/792 (2002)

7 ) Yanada, H., Inaba, T., Ichikawa, T.: Experimental Approach to Unsteady Friction Characteristics of a Hydraulic Motor in Low-Speed Range, Trans. Japan Soc. Mech. Eng. (Ser. B), 56-528, 2430/2437 (1990) (in Japanese) 
8 ) Yanada, H., Sekikawa, Y: Modeling of Dynamic Behaviors of Friction, Mechatronics, 18-7, 330/339 (2008)

9) Yanada, H., Takahashi, K., Matsui, A.: Identification of DynamicParameters of ModifiedLuGre Model Application to Hydraulic Actuator, Trans. Japan Fluid Power System Society, 40-4, 57/64 (2009)

10) Hibi,A.,Ichikawa, T::Influence ofHydraulicFluid on Torque Characteristics of Hydraulic Motor at Start and in Low
Speed Range, J. Japan Hydraulics and Pneumatics Society, 9-6, 418/422 (1978) (in Japanese)

11) Hess, D. P., Soom, A.: Friction at a Lubricated Line Contact Operating at Oscillating Sliding Velocities, ASME J. Tribology, 112-1, 147/152 (1990)

12) Inaguma, Y., Hibi, A.: Friction Torque Characteristics of a Vane Pump, J. Japan Hydraulics and Pneumatics Society, 25-7, 843/849 (1994) 